\title{
Managing a Multiethnic Class: What are Teachers' Perceptions and Decisions to Support Immigrant Students?
}

\author{
Rola Koubeissy \\ Canada
}

\begin{abstract}
This article interprets the perceptions and the reasons that induce teachers to make their decisions to support immigrant students in real class context, while taking into consideration the needs of other students. Based on the teaching work analysis approach and the concept of managing the unexpected, the article aims to explore the real work executed by teachers by virtue of classroom factors, and to search the reasons behind the actions they take in their classes. Drawing on qualitative interpretive methodology, data were collected through class observation, audio recording, and interviews with two teachers and their three immigrant students from two different highly diverse primary schools in Quebec. Findings show that teachers opt for collective, small group and individual support to cover their students' needs when they anticipate or discover students' difficulties. More specifically, the analysis of teachers' reasons shows that implementing and processing of individual teaching support practices are influenced by the perceptions and the decisions that teachers must make momentarily when they encounter a student difficulty. Teachers' decisions result from an inner negotiation process. They have to choose quickly between implementing supporting practices and maintaining their on-going prescribed tasks. More particularly, the teachers adopt four scenarios to manage the unexpected in their classes: 1- integrating the unexpected into the teaching activity, 2-considering the unexpected as a disruptive element, 3-exploiting the unexpected for the benefit of the class, 4- transferring the responsibility to the student.
\end{abstract}

\section{Introduction}

For the last decade, millions of people have immigrated and displaced from their homes to different countries for many reasons. For example, Quebec received more than 52400 immigrants in 2017 [9]. Immigrants have contributed to creating a multicultural society and to changing the sociocultural mosaic of the Quebec society recognized for its francophone cultural heritage. Therefore, schools are affected by the diversity of their students' body. To manage this diversity and to support the students in their integration into French schools, many measures and policies have been established in Quebec since the 1960s. A welcoming class model was established in 1969 [9] in order to promote French acquisition and citizenship education among students who recently arrived in Quebec. For the same reason, the Linguistic Policy was issued in 1996 to reinforce the use of French and to encourage schools to facilitate the linguistic integration of immigrant students [17]. In addition to the language aspect, the Policy Statement on Educational Integration and Intercultural Education published in 1998 urges teachers to facilitate immigrant students' social and cultural integration and to encourage them to value their own culture as well as other cultures. This Policy defined Intercultural Education as the ideal way to live together in a democratic, pluralist and francophone society.

Thus, teachers are expected to deal with this diverse context and to integrate these plans and measures into their teaching work. More specifically, they are expected to support immigrant students in their cultural, linguistic and academic integration while taking into consideration the needs of other students. They have to execute their daily tasks and address the difficulties that emerge in their classes. Piquemal, Bolivar and Bahi [18] describe teachers' work in this context as a difficult task accompanied by pedagogical adaptation and adjustment according to the needs and levels of their students. Gérin-Lajoie [7] also considers that this work is complex because of the triple task the teachers perform, which consists of transmitting knowledge to their students, socializing them and supporting them in their cultural and linguistic integration. Actually, in the real class context, teachers need to administer all their prescribed work such as preparation, students' evaluation, managing resources, meetings, report cards, and to arrange all incidents and events that appear in class. The teacher is responsible for ensuring the learning of all students, regardless of their culture. $\mathrm{He}$ is also asked to support immigrant students in the language of instruction, to help them in their social integration, to recognize the linguistic and cultural repertoires in his class, to provide diverse resources and to develop a favorable exchange environment for all students while taking into account all the class characteristics.

In relation to this multicultural context, this article aims to explore the teachers' perceptions and reasons that induce them to make their decisions to consider 
the immigrant students' difficulties and to support them in the real context of a regular classroom.

\section{Theoretical framework}

To explore this article objective, we proposed a theoretical framework inspired by the teaching work analysis approach [1], [5], [11], [20]. This approach helps us to understand the way teachers take class factors into consideration when deciding to implement practices of support. In relation to the same approach, we referred also to the concept of "managing the unexpected" [10]. This allows us to interpret the teacher's perceptions and reasons for acting in terms of what is expected and what is unexpected in the classroom.

In fact, teacher's duties refer to everything done in and out of class to teach students. In the context of this article, the teaching work consists also in considering certain new measures and action plans concerning integration of immigrant students. While some of the teaching work is planned to meet curriculum and policy requirements, another emerges in the action depending on student input and classroom context. Thus, we refer to the distinction established, among others, by ergonomists and sociologists of work between the prescribed and real work of the teacher.

\subsection{Prescribed and real teaching work}

Tardif and Lessard [20] consider that prescribed teaching work is planned, measured and similar for all teachers operating under the same educational system. This is called primary prescription [5]. It is related to governmental measures and plans that teachers are required to implement in with the curriculum, school policies, report cards, and other duties. It is also related to all class factors that may affect the teaching process. In addition to that, teachers can prescribe to themselves other tasks such as supporting the students in many domains, this is called secondary prescription or self-prescription [5]. It is defined according to teachers' visions and perceptions of their role in a multiethnic context and their responsibilities in integrating immigrant students.

However, teachers couldn't necessarily implement all of the prescribed work. In their multiethnic classes, they may face many incidents, unexpected situations and behavior on the part of their students. The prescribed work as it is redefined by teachers and established effectively in classrooms is called real work [11]. It consists of actions that are adjusted according to prescriptions and to the context of the class [4] and according to teachers' interpretation of each situation. It is an articulation between the unexpected and the events that emerge in the class [10]. Jean and Étienne [10] define the unexpected as any action or activity which occurs suddenly, likely to influence the situation. The unexpected is managed by teachers in terms of perceptions, decisions and treatment. In particular, the unexpected that emerges in the classroom is perceived or not by teachers. If it passes without being perceived, it has no effect on the flow of the current teaching activity. If teachers perceive it, they have to make decisions to manage it: either they ignore it in order to focus on the intended activity or they consider it. If teachers value the unexpected and give it enough importance, they tackle it and turn it into an event. They integrate it into the teaching activity and transform it into a learning opportunity for the student himself or for the whole [10]. For example, teachers may transform difficulties noticed among immigrant students during the action, or difficulties that students report themselves during the performance of a task, into supportive practices. This influences the flow of the main activity implemented in the class, the management of the time allocated to the activity, the supervision of the classgroup, and the order established in the classroom, especially if the task is carried out collectively in a large group.

So, real work is a continuous process of internal negotiation about what teachers have to decide to consider or ignore in a class to respond to students' difficulties. The decision made by teachers is envisaged in terms of dilemmas and tensions and derives from teachers' internal negotiation process between their prescriptions and the unexpected [4]. There is a responsibility to be defined before. Teachers' tensions result from their feeling of responsibility for what is prescribed, their lesson objectives and planning, but also from their responsibility regarding the unexpected student's difficulty. Consequently, teachers may decide to adjust their action and implement supportive teaching practices among immigrant student. The tension and the decision depend both on the way teachers conceive their role in the class and lean on their understanding and their vision of the situation in which they intervene [2]. For example, they may or may not perceive themselves as responsible for immigrant students' difficulties. Doing so, teachers seek to avoid costs and gain benefits from the decisions and choices they make in the action [12]. Although this can deprive a student from a learning opportunity, but in terms of benefits, teachers maintain order in the classroom. Thus, when turning the unexpected into an event, a student benefits from a learning opportunity, but teachers may lose order in the classroom. Conversely, opting for individual support is more beneficial to a student, but in terms of costs, teachers need to put more effort and energy into maintaining order in the classroom.

Hence teaching practices of support was defined as the real work that teachers do in class to support immigrant students while taking into consideration other classroom factors. The implementation of the practice of support: its form, the tool used, the actions 
of teachers and the interactions are also indicative of a reasoning in the action. Indeed, the way in which the unexpected is handled has an effect on the event itself. Like the decision, the treatment is also considered in the form of tensions. The event built in the action stems from a negotiation process. For example, a teacher who attaches great importance to the unexpected devotes more time to the event. Also, an unexpected that emerges during a collective activity is treated differently from a one that occurs within an individual activity. In short, the real work is the articulation between the primary and the secondary prescriptions and all that emerges in class, including the unexpected and the uncertainties [1].

\section{Methodology}

The data used in this article is part of a thesis research project about teaching practices to support immigrant students who have recently arrived to Quebec and integrated into regular primary classrooms. Drawing on qualitative interpretive methodology [19], a multi-case study (two cases) [16], data were collected through class observation, audio recording, and interviews with two teachers and their three immigrant students from two different highly diverse primary schools in Quebec. Two classes were selected (grades three and six) rich in interaction between teachers and students. They contained immigrant students who had not mastered the French language and do not have learning difficulties. The first case consists of a grade six teacher and one immigrant student while the second case involves a grade three teacher and two of her immigrant students.

\subsection{First Case: Teacher Carla, Student Jana}

This grade six class contains 23 students, of whom 16 are immigrants. The teacher, Carla, has a baccalaureate in primary education. She has nine years of experience. She has been teaching grade six for two years. She mentioned that her lessons are always pre-planned. Carla has previously taught in a mono-ethnic school, so she is aware of the difference between teaching immigrant students and native students. She stated that she is adapting herself to the multicultural class and is aware of her students' needs in such a context. However, she revealed that she should not be solely responsible for the support that Jana (the participant and the new immigrant student) requires. She explained that she has to take into consideration the particularity of the class and other students' needs.

Jana, the student, was born in North Africa. She arrived to Quebec in 2011. She has passed one-year in welcoming class before integrating into the grade six regular classes. She refused the fact that she has linguistic challenges in French. Jana mentioned that she doesn't like to be supported in front of her colleagues.

\subsection{Second Case: Teacher Sophie, Students Tina and Windy}

The grade three classes contain 25 students, of whom 15 are immigrants. Only Windy has passed the welcoming class. The teacher, Sophie, has a baccalaureate in primary education. She has had 14 years of experience in deprived and rich schools. Currently, she is a grade three class tutor as well as a part time teacher. Sophie said that she has adapted to teaching in a multiethnic context, and that she promotes Quebec culture in order to help immigrant students further integrate. At the same time, she implements different activities related to her students' cultures. Sophie believes that supporting her immigrant students is a part of her teaching duty. This is why she always takes the initiative to stimulate the students and evaluate their understanding during tasks and activities.

The student, Windy, moved from Asia to Quebec three years ago. She has passed two years of the welcoming class before integrating into grade three. She reads and speaks her native language at home. She knows English as well. She mentioned that she prefers her previous school in Asia because she could more easily express herself. She insisted that she doesn't have any difficulty in French language although she has. The second student, Tina, arrived in Quebec when she was two years old. She reads and speaks her mother tongue, particularly because her parents don't know any French.

\subsection{Data Presentation and Analysis}

Through class observation that lasted for three months, nine learning situations rich in interaction between the teachers and the participants were documented (fours situations from grade 6; and five from grade five). Then, 22 units of observation called sequences of support (nine from grade six; and 13 from grade three) were selected. Each sequence of support is defined as an interaction between a teacher and participant student(s) aiming to support, through the use of a tool, a student or a group of students in a difficult task. To deepen the understanding of the sequence of support, we interviewed the participants to get their points of view about the support offered and to understand their roles in constructing the practices of support. The interviews helped them to explain their actions and to identify and describe their strategies related to the sequences of support. In addition, we interviewed the participants before the data collection and at the end in order to know their personal information, teachers' role and prescribed tasks.

The data were presented in the form of tasks and 
learning situations. Every task was illustrated by one or more sequences of support. Each sequence of support was divided into two phases. The first one corresponds to the direct interaction between each teacher and her student(s). The duration of this phase differs from one sequence to other. This is followed by the second phase, which corresponds to the interaction of the student by herself (what the student is doing after the support). These two phases were preceded by trigger elements, which refer to the elements that provoked the support. After this, the points of view of both teachers and students about the sequences of support were presented. To present the data, we started with a horizontal analysis for each case followed by a synthesis of the same case. Then, we ended by a transversal analysis for both cases and we issued general findings.

\section{Findings}

For the purpose of this article, we will present the findings that are essential to answer the main question about the perceptions and the reasons that lead teachers to support immigrant students in the real class context. Through the 22 sequences of support, and based on interviews, three types of trigger elements that provoke support among immigrant students were noted. These three types prompt teachers to support students while taking the class context into consideration. The first type is issued from an anticipated difficulty by the teachers before task implementation. In fact, their years of experience teaching in multiethnic contexts allow Carla and Sophie to anticipate linguistic difficulties among immigrant students, especially in written tasks. In general, anticipated difficulties are related to word meaning and text comprehension. The second arises from a difficulty noticed by the teachers during task execution. The teachers identify difficulties among their immigrant students while solving a particular task in mathematics, French writing and reading. In the face of these unexpected difficulties, the teachers intervene when it is possible to support their students individually. For example, 12 sequences of support out of 22 are interrelated to difficulties noticed by Carla and Sophie. In fact, class observations show that both teachers were able to identify these difficulties by questioning immigrant students and checking the progress of their work. The third stems from a difficulty mentioned by the immigrant student during task execution. In some tasks, students express their difficulties by themselves. However, observations show that this happens rarely, especially for Jana and Windy who both recently arrived in Quebec. Tina, on the other hand, is more comfortable asking for support. Based on these proclaimed difficulties, the teachers decide whether to take action in order to support the students. This decision may be made according to the teachers' judgement or perception of the situation. In fact, the teachers take many factors into consideration before supporting the whole class or spending individual time with the students to support them on solving the problem.

Along with that, it was also noted that the teachers opt for three forms of support, whole group, individual and small group support. The last one is observed once by one of the teachers. In general, the teachers adjust their practices according to the class context. For example, they didn't limit their intervention to individual support and plan in prior the collective and the small group support in order to bridge linguistic difficulties anticipated among immigrant students. This variety in using many forms of support allows teachers to control their classes by taking into consideration their students' need.

\section{Discussion}

In the following, we interpret the relation between the prescriptions, the unexpected and the events in the light of the context of the class and other factors. As already indicated, the secondary prescriptions correspond to the collective support that the teachers consider important before the beginning of the tasks. The unexpected corresponds to the difficulties noted by the teachers or reported by the students during the task, and the events are related to support practices. More specifically, we interpret the perceptions and the reasons that lead the teachers to address the anticipated difficulties and implement collective and small group support, and to consider the unexpected and to initiate an individual support.

\subsection{Take into account anticipated difficulties and opt for collective support}

Based on their experience, the two teachers expect immigrant students to have language difficulties. Thus, they adjust and plan their teaching accordingly in order to enable students to perform their tasks. This means that they accord some importance to these difficulties that may block the functioning of the immigrant students. Therefore, they turned the difficulties into events, that is to say, practices of collective or small group support. This is due to their sense of responsibility and their vision about the support in the classroom. Collective support is identified when the teacher targets the whole class to support students on a particular task before starting their individual work. We have detected five sequences of collective support out of 22. In fact, our findings show that the collective support related to the documented learning situation is always followed by individual support among immigrant students. In general, collective support was implemented at the beginning of a task when the two teachers anticipated linguistic difficulties among their immigrant students. For this reason, they decide to break the constraints of 
the classroom context to meet the linguistic needs of immigrant students and plan for collective support before asking the students to start working individually. In fact, the context of the classroom encourages teachers to plan to support the whole group, not a particular student. Teachers have developed learning opportunities for all students based on these difficulties [10]. In this case, the class is easier to manage: the teachers are not likely to lose the other students who get involved. In addition, they manage their time more effectively. It is noted that both teachers devote more time to group support than to individual support. On the same meaning, Fisher and Frey [6] consider that the first phase of their model of the gradual release of responsibility that aims to support the students and develop their autonomy is the focused lesson that is addressed to the entire class. Although this form of support helps teachers to manage their class and their time, it may have some limits in terms of covering the particular needs of each student. For this reason, the teachers act and opt for other forms of support.

\subsection{Take into account anticipated difficulties and opt for small group support}

The small group support consists of offering support to a particular group of students chosen by the teacher while the other students work individually. It followed the collective support given at the beginning of a task in reading for comprehension in grade three. In fact, the grade 3 teacher initiates a small group support to answer more specific difficulties for a group of students. This support is more personalized and more adapted to students' needs than the collective support, because the tool used is more interactive. There are more exchanges between the teacher and the small group. This helps her to easily detect their individual difficulties. At the same time, the students find more space to ask questions and express their difficulties. In terms of limit, the class management is not easily achievable as the teacher has to manage the other students in the class, but also the students of the subgroup. For example, in the sequence of small group support in grade 3, other students interrupted the teacher several times, and she had to stop her support and respond to them.

However, the teaching activity was not constructed only from what was planned and anticipated. During the activity, there are unexpected difficulties that emerge in class. As mentioned before, the teaching process is not limited to what is planned prior to class. During task resolution, some unexpected difficulties emerge. Teachers make decisions to consider them and to support students individually.

\subsection{Transform the unexpected difficulties in practices of support and opt for individual support}

During any class activity, the teachers may notice a difficulty among the immigrant student, or the student may report others. The teachers have to make a decision to ignore them or turn them into event. The teachers usually transform them into individual support to better respond to the particular difficulties of each immigrant student. Individual support means that the teacher offers individual support to one of her immigrant students in a specific task. 15 individual sequences out of 22 were identified. It is noted that for both teachers, the sequences of whole group support are followed by individual support. This finding is consistent with that of many researchers [8], [13], [14] who emphasized the difficulty for the teacher to cover the particular students' needs during the collective or small group support. However, unlike the group support where the teacher has the class-group, the individual support is more subject to contextual factors, because the teacher has to put more energy to manage the other students at the time of her individual interaction with the immigrant student. Working individually with a student in the real context of the classroom requires at least that other students are busy with a task and that the teacher always have a look at them. As it has already said, the decision is the result of an internal negotiation between the prescriptions and the unexpected. There is previously a tension between respecting the planning of the activity or taking into consideration the unexpected. Depending on the importance of the difficulties they perceive, the teachers make the decision to take these unexpected into account. They treat and transform them into learning opportunities for the student. Each sequence of support is built in the action following a decision made by the two teachers, and a treatment of the difficulty that takes into account the factors of the context. In order to better understand how the teachers, perceive the situation and the reasons for them to take into account the unexpected and treat them differently, we interpret four sequences of support, two sequences from each teacher. Four scenarios are in place.

5.3.1. The management of the unexpected: integrating the unexpected into the teaching activity. The task in grade six is about a self-correction written French text done by the students. While each student is working on his own, Jana calls the teacher who comes to her desk. She asks a question about the meaning of a French word (bizarre). The teacher perceives the unexpected and decides accordingly to support Jana through a dialogue that lasts 2 minutes and 40 seconds instead of giving her the answer. It is obvious that the teacher decides to incorporate the unexpected into her teaching activity. The contextual 
factors increase the teacher's room for maneuvering in her interaction with Jana, especially that her decision to handle the unexpected did not affect how the activity was conducted in class, as each student is working individually. In fact, in this individual support sequence, the teacher was anticipating that any student may ask a question during the task. This is due to the nature of the task itself and the class factors. In this sense, the internal negotiation between the prescribed and the unexpected is not so much in conflict. As a result, the teacher devotes several minutes to support Jana and takes also into account the new difficulties that emerge at the moment during the interaction. The class is under control and the teacher has time to support Jana in other difficulties that appear. In this situation, the treatment of the unexpected is more considered in terms of benefits: Jana takes advantage of the event without any costs incurred for other students in the class who have continued their work. Along with that, the teacher attends to manage her class and the time allocated for the task without fear that her involvement with Jana will affect other students in the class.

5.3.2. The management of the unexpected: considering the unexpected as a disruptive element. Unlike the scenario described before, this sequence of support wasn't expected by the teacher. Thus, she perceives it and acts differently to not affect her class management and flow. The task is in grade six. It is about solving a math exercise as a part of a learning situation on the concept of rounding. The students have to solve the exercise individually, then to correct it with the teachers in the whole group. Jana participates and gives a wrong answer. This wrong answer wasn't anticipated by the teacher as it emerges during a collective teaching activity. At that moment, the teacher has to make a quick decision regarding the transformation of the unexpected into an event. Should she support Jana and affect the other students' momentum or interrupt the collective teaching activity? Actually, the teacher's sense of responsibility to Jana, which at some point defines her self-prescription, urges her to decide to support her instead of giving her a direct answer. She wanted to make the student realize that she was wrong and wanted to allow her to review the steps in her head. The teacher might not have gone to the end of her support with the student to maintain the still fragile balance in class [4], but she did not want to miss a learning opportunity for the student. Carla talked with Jana in front of the whole class through a dialogue that lasted two minutes. To do this, she cuts off the activity that takes place by stopping the resolution of the exercise with the other students. Her decision to implement the supportive practice accompanied by a deviation from her prescriptions changed the flow of her planned activity. This also has an impact on her interaction with the other students and with Jana. For this reason, during her interaction with Jana, she quickly takes control of the support because the time factor restricts her choices. Consequently, Jana doesn't have time to recognize her mistake. During the interaction, a new tension is envisaged for Carla, she has to choose between ending the support and the resumption of the teaching activity. Indeed, the fact that the other students in the class are waiting for the teacher to continue the correction of the exercise encourages her to cut off the support and to give a quick response to Jana. She imposes, according to the terms of Mencacci and Guélidi [15], limits to take the class in hand after each break of the teaching activity. She doesn't want to lose her students. In this sequence, in order to preserve a minimum of a class momentum, the teacher composed with the unexpected as a disruptive agent of the activity and did not transform it into a learning opportunity for all students. A new scenario is presented in the following.

5.3.3. The management of the unexpected: exploiting the unexpected for the benefit of the class. This task is a part of a learning situation in Frenchdictation. Although the teaching activity takes place collectively, the teacher manages the unexpected differently compared to the above scenario. Grade 3 students perform a dictation of prepared words every Thursday. During the revision period, the teacher asks one of the participant students, Tina, about the meaning of the word "advantage". Tina answers in the negative. The teacher gives sufficient importance to this unexpected and decides to adjust her teaching right away and intervenes by interrupting the flow of the activity. She exploits the unexpected and turns it into a learning opportunity not only for Tina, but for all the students in the class. To manage the group, she involves the other students in support by asking them related questions. The teacher explains the meaning of the word for 4 minutes 45 seconds for the whole class. By doing this, she reduces the costs of her decisions regarding the disruption of the activity and the management of the class. During the interview, she mentioned that this word is "important" for all students, so she has to spend time to explain its meaning. In this sequence, the teacher turns the class context to the benefit of the whole group and acts rapidly to manage the order among the group. In the last sequence that follows, the grade 3 teacher makes compromises when treating the unexpected. She keeps order in class through the implementation of an indirect mediation tool.

5.3.4. The management of the unexpected: transferring the responsibility to the student. This task in grade 3 is a writing assignment about students' favorite character related to four stories they read in class. The teacher allocates 90 minutes for the students to complete their work. 10 minutes before the end of the task, the teacher takes the initiative to check 
the notebook of one of the participant students, Windy. She noticed that she did not write anything. The teacher decides to turn the unexpected that emerges into an event and not to miss a learning opportunity for Windy. However, she has to keep order in the classroom and to meet the needs of other students, especially since the time assigned for the activity is only 90 minutes. She decides to make a compromise and uses indirect mediation support and transfers to Windy the responsibility of carrying out the task. She reacts quickly by offering Windy a support tool: the story that Windy is trying to write about, as she believes that Windy does not remember stories. This decision arises from an internal negotiation and tension between her responsibility for Windy and her responsibilities for the other students in the class. In fact, before offering the tool to Windy, the teacher begins her intervention with a question about the meaning of the text. Windy didn't know how to answer, so the teacher tries to manage the class well and to circumvent the limits of the context. She refers to the indirect mediation that consists in setting up a tool without the teacher being physically present at the time of the support, so she can maintain her interactions with the class-group and at the same time to give importance to the unexpected and to turn it into an event.

\section{Conclusion}

In the real class context, teachers are constantly searching for the best situation for their students, including immigrant students. They are called to provide a particular support for the immigrant students who recently arrived to Quebec and don't master the French language yet. The purpose is to help them overcome the linguistic and cultural barriers. In this context, the teaching work becomes more complex in terms of managing the diversity and covering all students' academic needs. Our findings show that the teachers use three forms of support as an adjustment made according to their students' needs. While it is manageable for them to opt for the collective and small group support, individual support requires a particular setting related to the class context, the flow of the pre-planned teaching activity, and other prescriptions. To make a decision to ignore or to consider the immigrant student difficulty and implement an individual support, teachers try to balance between their responsibility for the immigrant students and the teaching activity and the needs of other students. For this reason, they negotiate the situation internally in terms of cost and benefits and opt for different ways to treat the event. For example, due to their experience, the two teachers transform the anticipated linguistic difficulties into planned activities and opt for the collective group work although the difficulties concern only the immigrant students. This is due to the importance they accord to these difficulties in a multiethnic class. In addition, this is a good management of class and time. Thus, the teachers always make decisions to implement an individual classroom support, where possible, to meet the unique needs of each student, especially when the unexpected emerge in class during the completion of the task. Many reasons led teachers to deal with unexpected events differently from one sequence to another and to implement supportive teaching practices differently. They adopt four scenarios: they integrate the unexpected into the teaching activity, they consider it as a disruptive element, they exploit it for the benefit of the class, or they transfer the responsibility to the student. Finally, it is important to mention that these individual practices of support have their impact on the students' input, and the negotiation of the sense of support leading to the coconstruction of practice of support. This is an area that seems important to explore in another article.

\section{Conclusion}

[1] R. Amigues, "Pour une approche ergonomique de l'activité enseignante », Skholê, hors série, 2003, pp. 5-16.

[2] F. Beauregard, «Représentations sociales des parents et des enseignants de leurs rôles dans l'intégration scolaire d'un élève dysphasique en classe ordinaire au primaire ", Revue de sciences de l'éducation, 2006, pp. 545-565.

[3] M.F. Benes, S. Dyotte, "L'intégration des jeunes immigrants et immigrantes à l'école québécoise », VEI Enjeux, 2001, pp. 146-158.

[4] Bucheton, D., L'agir enseignant : des gestes professionnels ajustés, Octarès, Toulouse, France, 2009.

[5] S. Courally, « L'acculturation à l'écrit dans les pratiques et les instruments des maîtres en situation d'enseignement du français, langue de scolarisation », Revue des sciences de l'éducation, 2009, pp. 415-432.

[6] Fisher, F., Frey, N., Better learning through structured teaching, ASCD, Virginia, 2008.

[7] D. Gérin-Lajoie, « Le rôle du personnel enseignant dans le processus de reproduction linguistique et culturelle en milieu scolaire francophone en Ontario ", Revue des sciences de l'éducation, 2002, pp. 125-146.

[8] A. Hobsbaum, S. Peters, S. and K. Sylva, "Scaffolding in reading recovery", Oxford Review of Education, 1996, pp. 17-35.

[9] Institut de la Statistique du Québec, Le bilan démographique du Québec, Quebec, 2018. Retreived on: :http://www.stat.gouv.qc.ca/statistiques/p opulati ondemographie/bilan2018.pdf.

[10] Jean, A., Étienne, R., « La gestion des imprévus par un professeur stagiaire ", in D. Bucheton (EDs.), L'agir enseignant: des gestes professionnels ajustés (1e éd.), Ocateres, Toulouse, France, 2009. 
[11] Lessard, C. « Le travail enseignant, entre les effets structurants des politiques et l'activité en classe, la part des sujets ». in F. Yvon et F. Saussez (EDs), Analyser l'activité enseignante: des outils méthodologiques et théoriques pour l'intervention et la formation, PUL, Quebec, 2010, pp. 283329.

[12] A. Malo, « Appréciation des stagiaires au sujet des apprentissages effectués en stage en contexte d'enseignement », Éducation et francophonie, 2010, pp. 7895. Retreived on: http://www.acelf.ca /c/revue/pdf/EF-382-078_MALO.pdf.

[13] B. Maloch, "Scaffolding student talk: one teacher's role in literature discussion groups", Reading Research Quarterly, 2002, pp. 94-112.

[14] J. Masters, N. Yelland, "Teacher scaffolding: an exploration of exemplary practice", Education and information technologies, 2002, pp. 313-321.

[15] Mencacci, N., Guélidi, C., « Construire une limite pour prendre la classe en main. Le cas de Camille: la limite qui donne corps », in M. Vial (EDs), Le travail des limites dans la relation éducative: Aide? Guidage? Accompagnement ? L'Harmattan, Paris, France, 2010.

[16] Merriam, S. B., Case Study Research in Education, Jossey-Bass, Californie, 1988.

[17] M. Pagé, M., P.Lamarre, P. «L'intégration linguistique des immigrants au Québec », Quebec, 2010, retreived on : http://www.im.metropolis.net/medias/irpp_study_no3.pdf.

[18] N, Piquemal, B. Bolivar, and B. Bahi, « Nouveaux arrivants et enseignement en milieu franco-manitobain : défis et dynamiques », Cahiers franco-canadiens de l'Ouest, 2009, pp. 329-355.

[19] Savoie-Zajc, L., «La recherche qualitative/interprétative en éducation ». in T.Karsenti et L.Savoie-Zajc (EDs), La recherche en éducation : étapes et approches, Éducation-Innovation-Passion, Quebec, 2011, pp. 123-146.

[20] Tardif, M., Lessard, C., Le travail enseignant au quotidien, PUL, Quebec, 1998. 